\title{
Effects of Alprazolam and Clonazepam on Blood Sugar in Patients with Panic Disorder
}

\author{
Ali Akbar Moghadamnia' (1), Sussan Moudi² (D), Narges Tamaskani ${ }^{3}$, Mohamad Saleki ${ }^{4}$ (D) Angela Hamidia ${ }^{5}$ (D), \\ Marjan Mouodi' ${ }^{(1)}$, Ali Bijani ${ }^{7}$
}

'Department of Pharmacology, Babol University of Medical Sciences, Babol, Iran

2Department Social Determinants of Health Research Center, Health Research Institute, Babol University of Medical Sciences, Babol, Iran ${ }^{3}$ Department of General Practice, Faculty of Medicine, Babol University of Medical Sciences,

${ }^{4}$ Department of Internal Medicine, Yahyanejad Hospital, Babol University of Medical Sciences, Babol, Iran

${ }^{5}$ Department of Psychiatry, Babol University of Medical Sciences, Babol, Iran

${ }^{6}$ Department of Internal Medicine, Tehran University of Medical Sciences, Tehran, Iran

${ }^{7}$ Department Social Determinants of Health Research Center, Health Research Institute, Babol University of Medical Sciences, Babol, Iran

ORCID IDs of the authors: A.A.M. 0000-000I-7I40-I352; S.M. 0000-0002-6573-8861; N.T. 0000-000I-9549-8195; M.S. 0000-0003-I3666939; A.H. 0000-0003-3II3-2383; M.M. 0000-0002-5I38-4855; A.B. 0000-0003-2233-8726.

Cite this article as: Moghadamnia AA, Moudi S, Tamaskani N, Saleki M, Hamidia A, Mouodi M, et al. Effects of Alprazolam and Clonazepam on Blood Sugar in Patients with Panic Disorder. Cyprus J Med Sci 2019; 4(3): 195-200.

\section{BACKGROUND/AIMS}

Panic disorder is one of the most common anxiety disorders with a good pharmacotherapeutic response. Benzodiazepines are one type of such efficient medications. This study aimed to evaluate the impact of alprazolam and clonazepam on blood sugar of adults with panic disorder.

\section{MATERIAL and METHODS}

This randomized controlled trial recruited 45 patients suffering from panic disorder. After filling out the initial questionnaire and measuring patients' height and weight, fasting and 2-hour postprandial blood sugar and glycosylated hemoglobin (HgAlc) were measured. Then, the patients were randomly allocated into three groups of sertraline, sertraline+alprazolam, and sertraline+clonazepam. After 3 months of treatment, the lab tests were repeated, and the data were analyzed using the statistical analysis software SPSS I8.

\section{RESULTS}

A total of 32 women and 13 men with a mean age of $28.98 \pm 6.8$ years were recruited. Demographic characteristics and history of physical and psychological diseases did not show any significant differences among the three groups $(p>0.05)$. At the end of the 3rd treatment month, the mean of 2-hour postprandial blood sugar ( $p=0.032)$ and HgAlc $(p=0.0007)$ were decreased in the sertraline group, while the mean level of fasting blood sugar $(p=0.006)$ and 2 -hour postprandial blood sugar $(p=0.015)$, and HgAlc $(p=0.015)$ revealed a significant increase in the sertraline+alprazolam group.

\section{CONCLUSION}

This study showed that the treatment with alprazolam can cause an increase in the blood glucose in non-diabetic patients suffering from panic disorder.

Keywords: Alprazolam, blood sugar, clonazepam, panic disorder

\section{INTRODUCTION}

As a common anxiety disorder, panic disorder has a prevalence ranging from $1 \%$ to $2 \%$ in the lifetime of the general population (I). Pharmacotherapy and cognitive psychotherapy are the two effective treatment methods (2). Benzodiazepines are among the fast-acting anti-panic medications that can be used in a short-term and long-term treatment (3-6). On the other hand, it may take up to several weeks to achieve the therapeutic effect of selective serotonin reuptake inhibitors (SSRIs), and benzodiazepines represent the best treatment option, especially in the first few weeks. Among benzodiazepines, alprazolam (Xanax) is one of the most widely used medications for panic attacks (7-9), although similar effects were reported for lorazepam and clonazepam (10). Alprazolam reaches its maximum serum concentration I to 2 
hours after taking a I mg dose, and it has a half-life of 9-16 hours (II). Alprazolam randomly binds to benzodiazepine GABA receptors (12) to reduce the general brain activity. In addition, the GABA system interacts with other neurotransmitters, including serotonergic, adrenergic, cholinergic, and opioid systems. The clinical effects of alprazolam in treating anxiety and depression occur through the interaction of alprazolam with serotonergic and adrenergic pathways in the limbic system, brain stem, and locus coeruleus (8). Like other benzodiazepines, clonazepam exerts its effect by binding to GABA receptors, and thus increases the inhibitory activity of this receptor (13). Previous studies have shown that clonazepam has significantly greater effects than placebo in the treatment of panic attack (14-16).

In addition to their psychological effects, benzodiazepines exert different metabolic effects (17-20). Many studies have investigated the metabolic effects of alprazolam on blood sugar levels in humans, and given the conflicting results they produced and because of the widespread use of alprazolam and clonazepam in the treatment of panic disorder, the present study aims to assess the effect of these medications on blood sugar levels in non-diabetic individuals suffering from panic disorder.

\section{MATERIALS and METHODS}

In the present randomized controlled trial, 45 patients visiting psychiatric departments affiliated to Babol University of Medical Sciences (Rouhani and Yahyanejad Hospitals) were randomly enrolled if they presented with diagnostic criteria for panic disorder according to the Diagnostic and Statistical Manual of Mental Disorders, $4^{\text {th }}$ edition (DSM-IV), as well as the study inclusion criteria.

The study inclusion criteria included the age $\geq 18$ years and older, a written consent form, psychiatric diagnosis of panic disorder based on the DSM-IV criteria (newly diagnosed patients), no intention of pregnancy during the study and using a suitable contraceptive method, and no use of psychoactive medications over the week.

The study exclusion criteria included active suicidal ideations; diseases in which sertraline, alprazolam, and clonazepam are contraindicated; a history of or current psychotic or bipolar disorder; pregnant or breastfeeding women, uncontrolled seizure disorder; a personality disorder that impairs assessment of treatment efficacy and safety, simultaneous treatment with psychotropic medications, and diabetes.

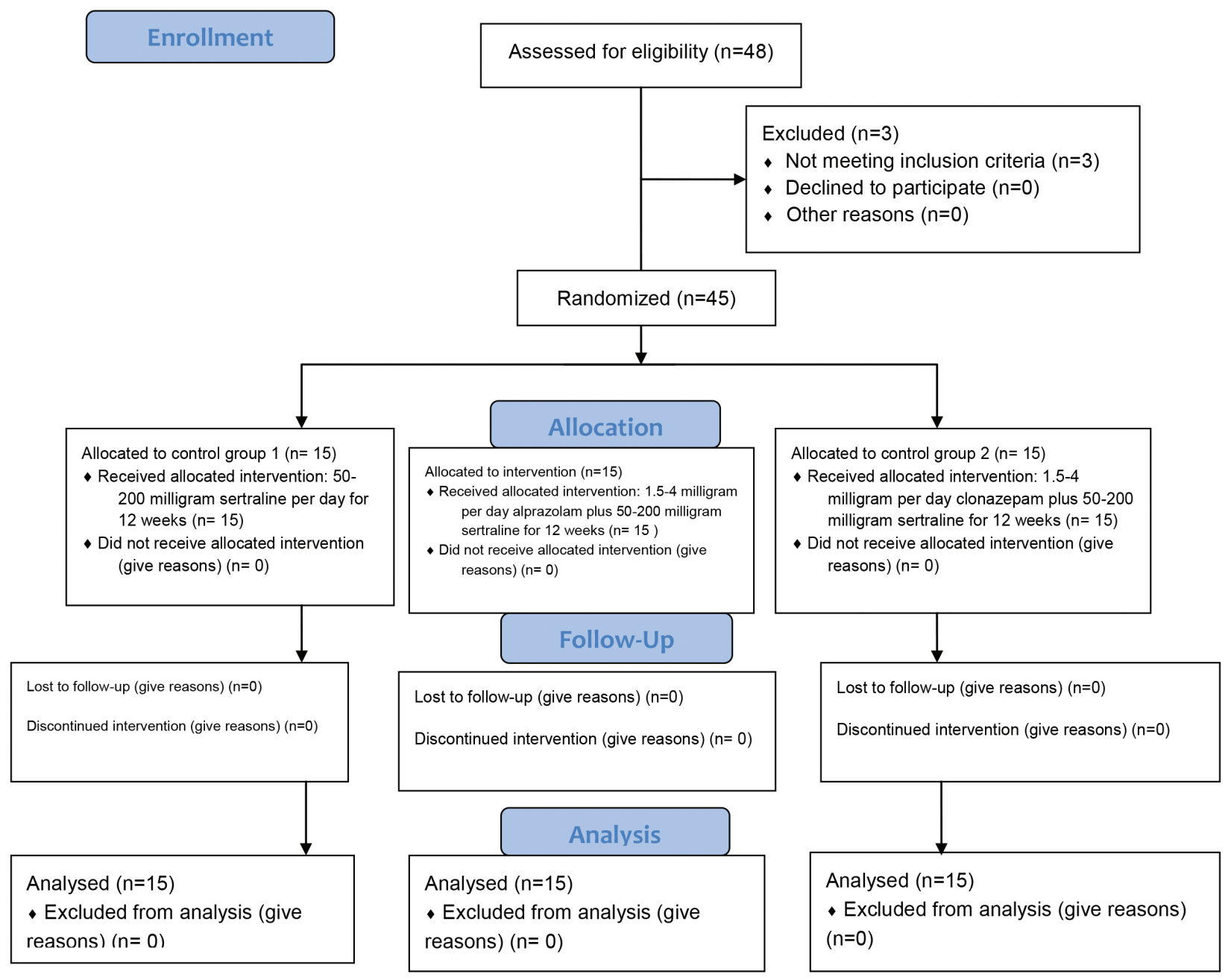


First, participants' demographic details (age, gender, education level, and marital status), history of physical and psychoneurological diseases, and frequency of panic attacks over the last week were recorded. Then, their height and weight were measured, and fasting and two-hour postprandial (2hpp) blood sugar, and $\mathrm{HbAlc}$ were assessed. Patients were randomly (in numerical order) allocated to sertraline, sertraline plus alprazolam, and sertraline plus clonazepam groups ( 15 patients in each group). Figure I presents the study process flowchart.

The case group (sertraline+alprazolam) received a daily dose of I-2 mg of alprazolam plus 50 mg to 200 mg of sertraline (depending on patient's response), and the control group (sertraline only) received $50 \mathrm{mg}$ to $200 \mathrm{mg}$ of sertraline per day. Considering that in newly diagnosed patients, the control of panic attacks (especially in the first weeks of treatment) is difficult, $0.5 \mathrm{mg}$ alprazolam was prescribed if required in case of a panic attack. The other control group (sertraline+clonazepam) received a daily dose of $0.5-1 \mathrm{mg}$ of clonazepam plus $50 \mathrm{mg}$ to $200 \mathrm{mg}$ of sertraline. Patients were studied over 12 weeks. At this stage, patients for whom a medical visit was necessary have been visited by the project psychiatrists, free of charge. At the end of the first treatment month, patients' body mass index was measured again, they were visited by the psychiatrist, and the frequency of their panic attacks was recorded. At the end of the 3rd treatment month, patients were visited by the psychiatrist, and their fasting and 2-hour postprandial blood sugar and $\mathrm{HbAlc}$ were evaluated again.

The ethics committee approval was received for this study from Babol University of Medical Sciences, Babol, Iran (Approval date: December 28, 2015; Approval number: Mubabol. Rec.1394.255). All participants provided an written informed consent form.

This study was registered on the website of clinical trials (wWw. irct.ir) with the registration ID: IRCT201604072299IN3.

\section{Statistical Analysis}

Data obtained from the three groups were analyzed using the IBM Statistical Package for the Social Sciences (SPSS) Statistics version 18 (SPSS IBM Corp.; Armonk, NY, USA). Chi-square and analysis of variance (ANOVA) tests have been used for data analysis; in addition to the ANOVA, repeated measure (general linear model) was used to assess the trend of blood glucose and $\mathrm{HbAlc}$ changes. Some of baseline variables such as drug dose have been considered as covariates in this analysis model. A $p$-value $<0.05$ was considered statistically significant.

\section{RESULTS}

Patients' mean age was $28.98 \pm 6.8$ years (range, 19-52 years). A total of eight patients were unable to complete the treatment course (due to medication side-effects or non-attendance). Physical diseases were reported by $31.1 \%$ of patients. Of all physical diseases reported, the mitral valve prolapse at II.I\% was the most frequent among patients with panic attack. Furthermore, $48 \%$ of patients had psychiatric comorbidities, of which, GAD at $17.7 \%$ and adjustment disorder at II.1\% had the highest prevalence. Other comorbidities were major depressive disorder, social phobia, $O C D$, and dysthymia, respectively. The mean number of panic attacks in the last week was $2.98 \pm 1.8$, which was reduced to $1.421 \pm 0.5$ after the first month of treatment and zero by the end of the 3rd month. This reduction was statistically significant $(p=0.002)$. Table I presents the blood sugar status of patients with panic attack before and after treatment in the sertraline, sertraline+alprazolam, and sertraline+clonazepam groups.

Figure 2 shows therapeutic effects of the three groups on HgAlc before and after the intervention. No significant dose-dependent effects were observed ( $p=0.807)$.

In terms of side-effects, 37 (82.7\%) patients experienced at least one side-effect, and the sertraline+alprazolam group had the highest side-effects; although generally, no significant difference was observed among the groups in terms of medication side-effects $(p>0.05)$. The most common side-effect was loss of appetite, as $44 \%$ of patients (four from sertraline group and three from sertraline plus clonazepam) experienced it. Meanwhile, $56 \%$ (eight from the sertraline+alprazolam group and one from the sertraline+clonazepam group) experienced increased appetite. No significant association was observed between se-

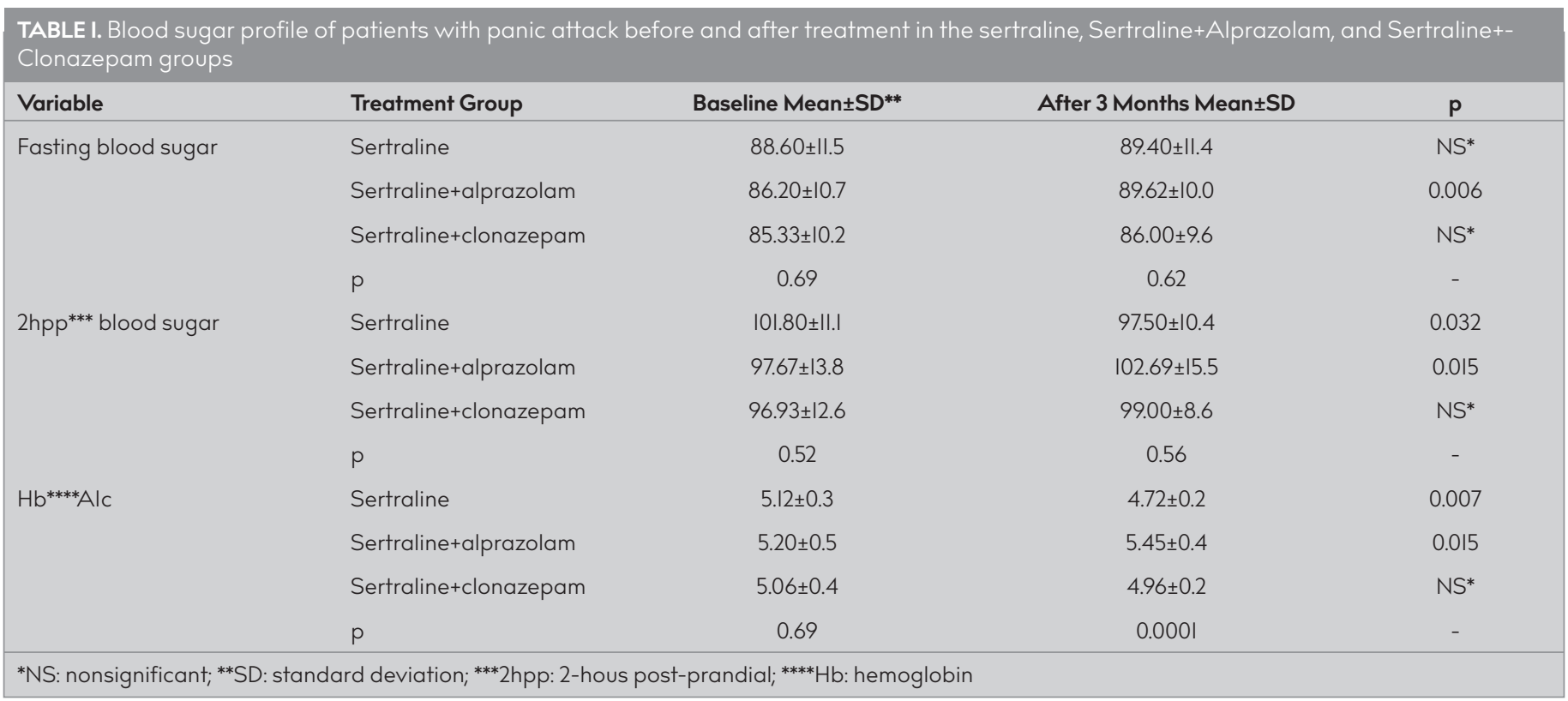




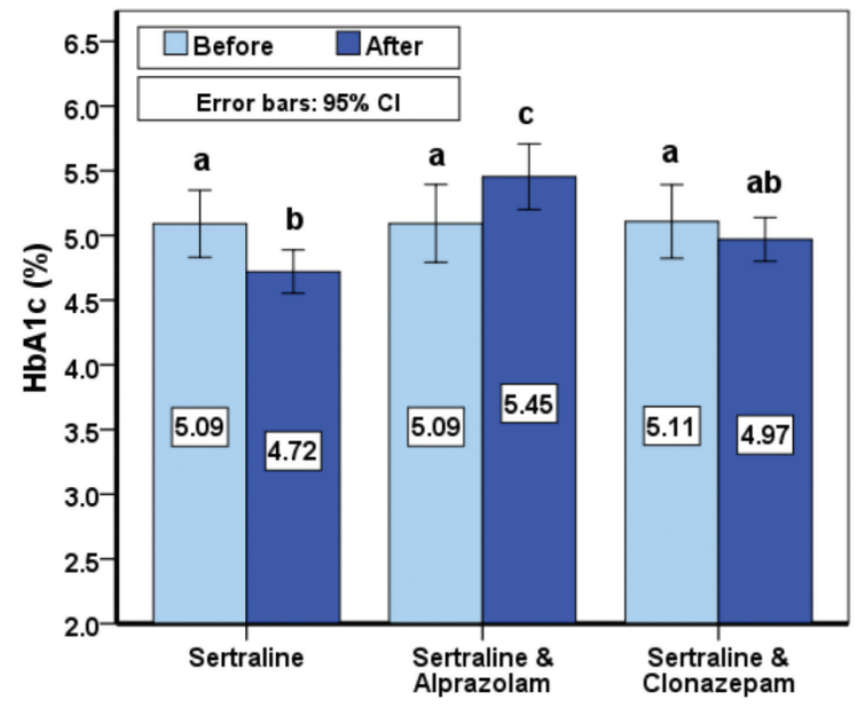

FIGURE 2. Effects of the three treatment groups on HbAlc (before and after the intervention)

rum glucose changes and weight gain ( $p>0.05$ ). Hypersomnia and sexual dysfunction were other common side-effects.

\section{DISCUSSION}

The present study showed a significant reduction in the 2-hour postprandial blood sugar $(p=0.032)$ and HbAlc $(p=0.007)$ in the sertraline group, and a significant increase in fasting $(p=0.006)$ and 2-hour postprandial $(p=0.015)$ blood sugar and $\mathrm{HbAlc}$ $(p=0.015)$ in the sertraline+alprazolam group.

Surwit et al. (2l) compared the effects of $5 \mathrm{mg} / \mathrm{kg}$ injection of alprazolam with placebo in diabetic rats and reported that alprazolam can increase plasma insulin and reduce blood glucose in response to stress. The difference between their results and ours appear to be caused by the fact that these authors assessed only the short-term effect of alprazolam on diabetic rats.

In a study by Lustman et al. (22), alprazolam reduced HbAlc over 8 weeks in diabetic patients with panic attack. Unlike the present study, their study was conducted on diabetic patients with uncontrolled blood sugar. Moreover, they assessed only the effect of alprazolam alone without sertraline, which can explain the difference in the results.

In a clinical trial conducted by Afkhami Ardekani et al. (23), the administration of fluoxetine led to significant reductions in blood sugar indices, including fasting and postprandial blood sugar and $\mathrm{HbAlc}$. The same result was observed in the present study for sertraline. Unlike the present study, in the Afkhami study, alprazolam led to reduced fasting and postprandial blood sugar and $\mathrm{HbAlc}$. Interestingly, their study population also had uncontrolled diabetes and had received alprazolam alone.

In another study, Afkhami investigated the effect of alprazolam on blood sugar control in diabetic patients and reported reduced fasting blood sugar (24). In the present study, the therapeutic effects of alprazolam and fluoxetine were compared, while we assessed the effect of sertraline+alprazolam as a treatment approach to panic disorder. The difference might be attributed to the study design (to use different SSRIs as treatment options) and the effect of sertraline on pharmacodynamics of alprazolam. Given that sertraline is an inhibitor of liver enzymes, especially cytochrome P450 (25), it can exert its effect by changing hepatic uptake and metabolism of alprazolam, and provide its different impact on blood glucose.

In a study by Gomez et al. (26), administration of sertraline led to no increase in blood sugar following glucose injection in both diabetic and non-diabetic groups of rats, and clonazepam caused no significant change in fasting and postprandial blood sugar in rats. The present study confirmed this finding as sertraline-reduced postprandial blood sugar and $\mathrm{HbAlc}$, but clonazepam caused no significant change in blood sugar indices.

In 1977, Zumoff and Hellman (27) revealed that daily intake of 40 $\mathrm{mg}$ of chlordiazepoxide in insulin-dependent diabetic women exacerbated hyperglycemia and increased fasting blood glucose from 220 to 380 . They also asserted that most analgesics exacerbate hyperglycemia and most antidepressants improve hyperglycemia. The present study results showed increased fasting blood sugar, $2 \mathrm{hpp}$, and HbAlc levels. Since the fasting blood sugar level is not a reliable criterion for long-term blood sugar control, HbAlc appears to be a more appropriate criterion for the assessment of the alprazolam effect.

In another review study, Mclntyre et al. (28) investigated the effect of antidepressants on blood sugar hemostasis and insulin sensitivity, and the showed that certain serotonergic medications such as fluoxetine reduce hyperglycemia and increase insulin sensitivity, while noradrenergic antidepressants such as desipramine have the reverse effect. Moreover, norepinephrine and serotonin reuptake inhibitors such as venlafaxine and duloxetine have no effect on blood sugar hemostasis.

In a clinical trial, Giardino et al. (29) investigated the effect of alprazolam on the neuroendocrine reaction of the body in response to hypoglycemia 120 minutes after administration. The results showed that alprazolam reduces $\mathrm{ACTH}$ and $\mathrm{GH}$ response to ITT-induced hypoglycemia butthat it has no effect on the level of cortisol. Alprazolam showed no effect on the hypoglycemia-induced glucose changes. In a similar study, Patel et al. (30) observed an increase in cortisol and ACTH due to hypoglycemia in the placebo group, but not in the alprazolam group. The results of a study by Hedrington et al. (3l) also confirmed the effect of alprazolam in reducing hypoglycemia-induced neuroendocrine effects in healthy people. However, the above studies investigated the acute effect of medication on fasting and postprandial blood sugar, but they did not measure HbAlc. It appears that alprazolam affects neuro-adrenergic systems in the short-term, inhibits them, and prevents blood sugar increase.

In the present study, sertraline was a fixed component of treatment in all three groups, and its blood-sugar-reducing effect was demonstrated. However, this effect was not observed in combination with alprazolam, and the blood sugar increased. The reason for the difference may be attributed to the combined use of sertraline and alprazolam as this combination changes its pharmacodynamics and its metabolism and can ultimately lead to increased blood sugar levels. 
One of the side-effects of alprazolam is impaired appetite. In the present study, this effect was observed as increased appetite in the sertraline+alprazolam group. The increase in appetite can be due to the direct effect of medication on the appetite center, or due to a sense of well-being and an improved clinical status.

The weight gain was also proposed as another side-effect of alprazolam. The sedation and lethargy induced by alprazolam can lead to inactivity or reduced physical activity, and in the long term, it can lead to weight gain and its subsequent complications, including insulin resistance.

Another significant clinical point in the present study was the lack of a significant change in the blood sugar profile in patients receiving clonazepam+sertraline. Compared to alprazolam, clonazepam appears to be a better treatment choice, especially for diabetic patients.

One of the strength points of the present study is the fact that many studies have assessed the effect of benzodiazepines such as alprazolam on the blood sugar profile of diabetic patients, but only a few studies have been conducted in non-diabetic patients. Another distinctive point in the present study was the assessment of a combined use of alprazolam+sertraline, while most studies have investigated the effect of alprazolam alone.

Limitations of this study included the difficulty of panic attacks control in the control group, especially in the first weeks of treatment when we prescribed $0.5 \mathrm{mg}$ alprazolam, as needed, in persistent panic attacks that did not respond to sertraline. It is suggested to future researches to design the study using a method in which the control group does not need benzodiazepines, although it seems very difficult.

The present study showed that alprazolam can increase HbAlc and thus affect the control of blood sugar in non-diabetic patients.

Ethics Committee Approval: Ethics committee approval was received for this study from the ethics committee of Babol University of Medical Sciences, Babol, Iran (Approval date: December 28, 2015; Approval number: Mubabol.Rec.1394.255)

Informed Consent: Written informed consent was obtained from patients who participated in this study.

Peer-review: Externally peer-reviewed

Author contributions: Concept - A.A.M., S.M.; Design - A.A.M., S.M.; Supervision - A.A.M., S.M.; Resource - A.A.M., S.M.; Materials - A.A.M., S.M., N.T., M.S., A.H., M.M.; Data Collection and/or Processing - A.A.M., S.M., N.T., M.S., A.H., M.M.; Analysis and/or Interpretation - A.A.M., S.M., A.B.; Literature Search - A.A.M., S.M., N.T.; Writing - A.A.M., S.M.; Critical Reviews- A.A.M., S.M.

Conflict of Interest: The authors have no conflicts of interest to declare.

Financial Disclosure: The authors declare that this study has been supported by Deputy of Research of Babol University of Medical Sciences, Babol, Iran

\section{REFERENCES}

I. Bighelli I, Trespidi C, Castellazzi M, Cipriani A, Furukawa TA, Girlanda $F$, et al. Antidepressants and benzodiazepines for panic disorder in adults. Cochrane Database Syst Rev 2016; 9: Cd0II567 [CrossRef]
2. Sawchuk CN, Roy-Byrne P, Noonan C, Craner JR, Goldberg J, Manson $\mathrm{S}$, et al. Panic attacks and panic disorder in the American Indian community. J Anxiety Disord 2017; 48: 6-12. [CrossRef]

3. Bruce SE, Vasile RG, Goisman RM, Salzman C, Spencer M, Machan JT, et al. Are benzodiazepines still the medication of choice for patients with panic disorder with or without agoraphobia? Am J Psychiatry 2003; 160(8): 1432-8. [CrossRef]

4. Perna G, Alciati A, Riva A, Micieli W, Caldirola D. Long-Term Pharmacological Treatments of Anxiety Disorders: An Updated Systematic Review. Current Psychiatry Reports 2016; 18(3): 23. [CrossRef]

5. Rosenbaum JF, Moroz G, Bowden CL. Clonazepam in the treatment of panic disorder with or without agoraphobia: a dose-response study of efficacy, safety, and discontinuance. Clonazepam Panic Disorder Dose-Response Study Group. J Clin Psychopharmacol 1997; 17(5): 390-400. [CrossRef]

6. Nardi AE, Valenca AM, Nascimento I, Lopes FL, Mezzasalma MA Freire RC, et al. A three-year follow-up study of patients with the respiratory subtype of panic disorder after treatment with clonazepam. Psychiatry Res 2005; 137(I-2): 61-70. [CrossRef]

7. Moylan S, Giorlando F, Nordfjaern T, Berk M. The role of alprazolam for the treatment of panic disorder in Australia. Aust N Z J Psychiatry 2012; 46(3): 212-24. [CrossRef]

8. Verster JC, Volkerts ER. Clinical pharmacology, clinical efficacy, and behavioral toxicity of alprazolam: a review of the literature. CNS Drug Rev 2004; 10(I): 45-76. [CrossRef]

9. Marquez M, Arenoso H, Caruso N. Efficacy of alprazolam sublingual tablets in the treatment of the acute phase of panic disorders. Actas Esp Psiquiatr 2011; 39(2): 88-94.

10. Nardi AE, Valenca AM, Freire RC, Mochcovitch MD, Amrein R, Sardinha A, et al. Psychopharmacotherapy of panic disorder: 8-week randomized trial with clonazepam and paroxetine. Braz J Med Biol Res 20ll; 44(4): 366-73. [CrossRef]

II. Ciraulo DA, Antal EJ, Smith RB, Olson DR, Goldberg DA, Rand EH, et al. The relationship of alprazolam dose to steady-state plasma concentrations. J Clin Psychopharmacol 1990; I0(I): 27-32. [CrossRef]

12. NuttDJ, Malizia AL. New insights into the role of the GABA(A)-benzodiazepine receptor in psychiatric disorder. Br J Psychiatry 200I; 179: 390-6. [CrossRef]

13. Kacirova I, Grundmann M, Silhan P, Brozmanova H. A case report of clonazepam dependence: utilization of therapeutic drug monitoring during withdrawal period. Medicine (Baltimore) 2016; 95(9): e288I. [CrossRef]

14. Valenca AM, Nardi AE, Nascimento I, Mezzasalma MA, Lopes FL, Zin W. Double-blind clonazepam vs placebo in panic disorder treatment. Arq Neuropsiquiatr 2000; 58: 1025-9. [CrossRef]

15. Beauclair L, Fontaine R, Annable L, Holobow N, Chouinard G. Clonazepam in the treatment of panic disorder: a double-blind, placebo-controlled trial investigating the correlation between clonazepam concentrations in plasma and clinical response. J Clin Psychopharmacol 1994; 14: III-8. [CrossRef]

16. Ontiveros A, Fontaine R. Sodium valproate and clonazepam for treatment-resistant panic disorder. JPN 1992; 17(2): 78-80.

17. Derijks HJ, Meyboom RH, Heerdink ER, De Koning FH, Janknegt R, Lindquist $M$, et al. The association between antidepressant use and disturbances in glucose homeostasis: evidence from spontaneous reports. Eur J Clin Pharmacol 2008; 64(5): 53I-8. [CrossRef]

18. Chevassus H, Mourand I, Molinier N, Lacarelle B, Brun JF, Petit P. Assessment of single-dose benzodiazepines on insulin secretion, insulin sensitivity and glucose effectiveness in healthy volunteers: a double-blind, placebo-controlled, randomized cross-over trial [ISRCTN08745124]. BMC Clin Pharmacol 2004; 4: 3. [CrossRef]

19. Surwit RS, McCubbin JA, Kuhn CM, McGee D, Gerstenfeld D, Feinglos MN. Alprazolam reduces stress hyperglycemia in ob/ob mice. Psych Med 1986; 48(3-4): 278-82. [CrossRef]

20. Vahidi A, Afkhami-Ardekani M, Vahidi MY, Rashidi M, Shojaoddiny-Ardekani A. Effect of Alprazolam on Serum Insulin Levels in Non-Diabetic Rats. IJDO 2012; 4(3): 105-8. 
21. Surwit RS, McCubbin JA, Kuhn CM, McGee D, Gerstenfeld D, Feinglos MN. Alprazolam reduces stress hyperglycemia in ob/ob mice. Psych Med 1986; 48(3-4): 278-82. [CrossRef]

22. Lustman PJ, Griffith LS, Clouse RE, Freedland KE, Eisen SA, Rubin EH, et al. Effects of alprazolam on glucose regulation in diabetes. Results of double-blind, placebo-controlled trial. Diabetes Care 1995; 18(8): II33-9. [CrossRef]

23. Afkhami Ardekani M, Shojaoddini Ardekani A, Soltani $\bigvee$, Molanoori E. Comparing the effects of Fluoxetine and Alprazolam on blood glucose in patients with type 2 diabetes. JQUMS 2008; I2(I): 2I-9.

24. Afkhami Ardekani M, Khani P. Effects of Alprazolam on Fasting Blood Sugar in Type II Diabetics. Journal of Sabzevar University of Medical Sciences, 2003; 10(4): 21-5.

25. Sadock BJ, Sadock VA, Ruiz P. Kaplan and Sadock's Comprehensive Textbook of Psychiatry. I0th edition. Philadelphia: Wolters Kluwer. 2017: 3164.

26. Gomez R, Huber J, Tombini G, Barros HM. Acute effect of different antidepressants on glycemia in diabetic and non-diabetic rats. Braz J Med Biol Res 200l; 34(I): 57-64. [CrossRef]
27. Zumoff B, Hellman L. Aggravation of diabetic hyperglycemia by chlordiazepoxide. JAMA 1977; 237(I8): 1960-I. [CrossRef]

28. Mclntyre RS, Soczynska JK, Konarski JZ, Kennedy SH. The effect of antidepressants on glucose homeostasis and insulin sensitivity: synthesis and mechanisms. Expert Opin Drug Saf 2006; 5(I): 157-68. [CrossRef]

29. Giordano R, Grottoli S, Brossa P, Pellegrino M, Destefanis S, Lanfranco F, et al. Alprazolam (a benzodiazepine activating GABA receptor) reduces the neuroendocrine responses to insulin-induced hypoglycaemia in humans. Clin Endocrinol 2003; 59(3): 314-20. [CrossRef]

30. Patel AX, Miller SR, Nathan PJ, Kanakaraj P, Napolitano A, Lawrence $P$, et al. Neuroendocrine and sympathetic responses to an orexin receptor antagonist, SB-649868, and alprazolam following insulin-induced hypoglycemia in humans. Psychopharmacol 2014; 23I(19): 3817-28. [CrossRef]

31. Hedrington MS, Farmerie S, Ertl AC, Wang Z, Tate DB, Davis SN. Effects of antecedent GABAA activation with alprazolam on counterregulatory responses to hypoglycemia in healthy humans. Diabetes 2010; 59(4): 1074-8I. [CrossRef] 